\title{
Assessment of the Requirements for Placing and Maintaining Savannah River Site Spent Fuel Storage Basins Under International Atomic Energy Agency Safeguards
}

\author{
O. P. Amacker, Jr. \\ M. M. Curtis \\ C. H. Delegard \\ S. T. Hsue ${ }^{(a)}$ \\ R. N. Whitesel ${ }^{(\mathfrak{b})}$
}

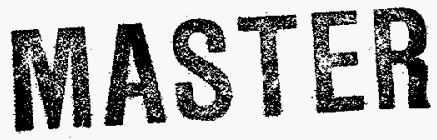

March 1997

Prepared for

DSTRESUTON OF THIS DOCUMENT IS

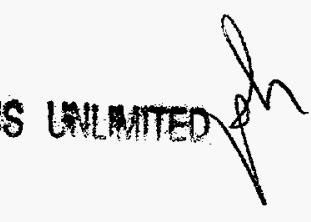

the U.S. Department of Energy

under Contract DE-AC06-76RLO 1830

Pacific Northwest National Laboratory

Richland, Washington 99352
(a) Los Alamos National Laboratory
(b) Jupiter Corporation 


\section{DISCLAIMER}

This report was prepared as an account of work sponsored by an agency of the United States Government. Neither the United States Government nor any agency thereof, nor any of their employees, makes any warranty, express or implied, or assumes any legal liability or responsibility for the accuracy, completeness, or usefulness of any information, apparatus, product, or process disciosed, or represents that its use would not infringe privately owned rights. Reference herein to any specific commercial product, process, or service by trade name, trademark, manufacturer, or otherwise does not necessarily constitute or imply its endorsement, recommendation, or favoring by the United States Government or any agency thereof. The views and opinions of authors expressed herein do not necessarily state or reflect those of the United States Government or any agency thereof. 


\section{DISCLAIMER}

Portions of this document may be illegible electronic image products. Images are produced from the best available original document. 


\section{Contents}

Summary and Conclusions $\ldots \ldots \ldots \ldots \ldots \ldots \ldots \ldots \ldots \ldots \ldots \ldots$

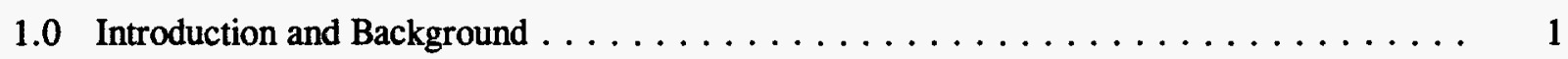

1.1 Eligibility Determination $\ldots \ldots \ldots \ldots \ldots \ldots \ldots \ldots \ldots \ldots \ldots \ldots \ldots \ldots \ldots \ldots$

2.0 Facility Descriptions and Operations $\ldots \ldots \ldots \ldots \ldots \ldots \ldots \ldots \ldots$

2.1 Spent Fuel Storage Configuration at SRS $\ldots \ldots \ldots \ldots \ldots \ldots \ldots \ldots \ldots \ldots \ldots \ldots$

2.2 Receiving Basin for Offsite Fuel (RBOF) $\ldots \ldots \ldots \ldots \ldots \ldots \ldots \ldots \ldots \ldots \ldots \ldots$

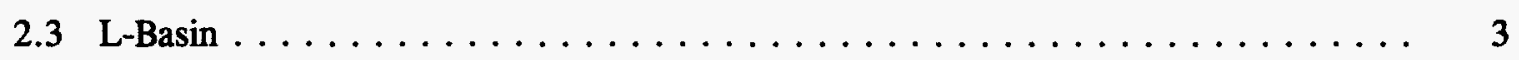

2.4 Receipt and Loading Schedules . . . . . . . . . . . . . . 4

3.0 Summary of IAEA Safeguards Criteria for SRS Research Reactor Spent Fuel $\ldots \ldots \ldots$

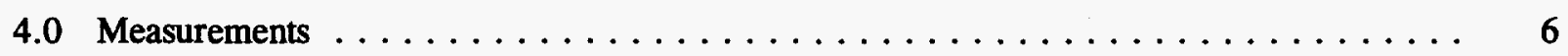

5.0 Containment/Surveillance Options $\ldots \ldots \ldots \ldots \ldots \ldots \ldots \ldots \ldots \ldots$

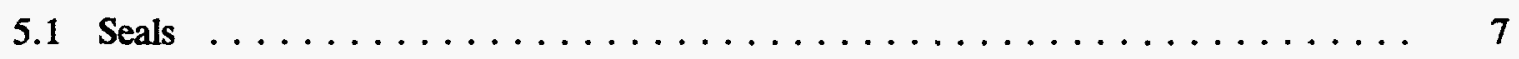

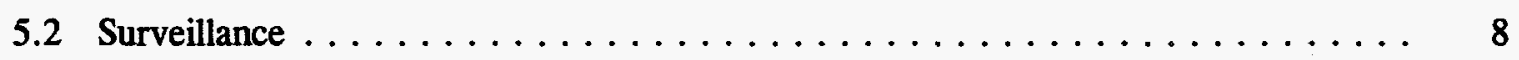

6.0 Cases $\ldots \ldots \ldots \ldots \ldots \ldots \ldots \ldots \ldots \ldots \ldots \ldots \ldots \ldots \ldots \ldots$

7.0 IAEA and Operator Resource Requirements $\ldots \ldots \ldots \ldots \ldots \ldots$

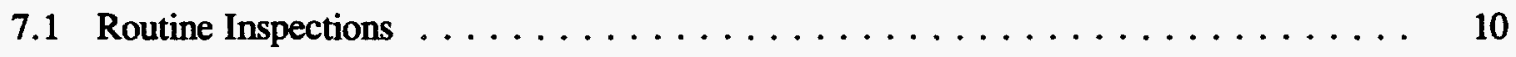

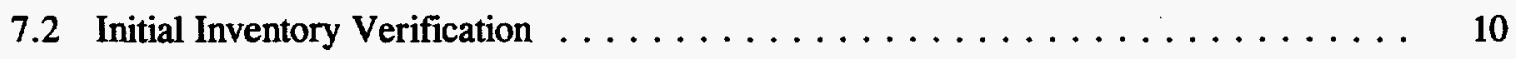

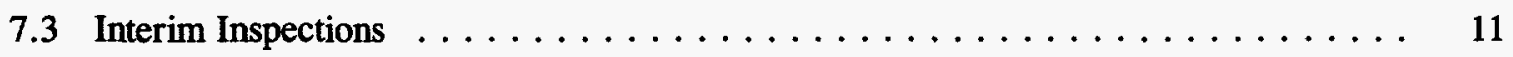

7.4 Physical Inventory Verifications $\ldots \ldots \ldots \ldots \ldots \ldots \ldots \ldots \ldots \ldots \ldots$

Appendix - IAEA Safeguards Criteria for Research Reactor Fuel $\ldots \ldots \ldots \ldots \ldots \ldots$. . . . . 


\section{Tables}

6.1 Case Descriptions and Requirements $\ldots \ldots \ldots \ldots \ldots \ldots \ldots \ldots \ldots$

7.1 Facility Selection Impacts $\ldots \ldots \ldots \ldots \ldots \ldots \ldots \ldots \ldots \ldots \ldots \ldots \ldots \ldots \ldots$

7.2 Facility Operations Impacts $\ldots \ldots \ldots \ldots \ldots \ldots \ldots \ldots \ldots \ldots \ldots \ldots$ 


\section{Summary and Conclusions}

The United States is considering the offer of irradiated research reactor spent fuel (RRSF) for international safeguards applied by the International Atomic Energy Agency (IAEA). The offer would be to add one or more spent fuel storage basins to the list of facilities eligible for IAEA safeguards. The fuel to be safeguarded would be stored in basins on the Savannah River Site (SRS). This RRSF potentially can include returns of Material Test Reactor (MTR) type fuel from Argentina, Brazil, and Chile (ABC); returns from other foreign research reactors; and fuel from domestic research reactors. Basins on the SRS being considered for this fuel storage are the Receiving Basin for Offsite Fuel (RBOF) and the L-Area Disassembly Basin (L-Basin). A working group of SRS, U.S. Department of Energy International Safeguards Division (NN-44), and National Laboratory personnel with experience in IAEA safeguards was convened to consider the requirements for applying the safeguards to this material. The working group projected the safeguards requirements and described alternatives.

The working group reached the following conclusions:

1. Imposition of IAEA safeguards for any of the three considered cases $(A B C$, all foreign, all foreign and domestic) requires common baseline costs and inspection frequencies.

2. Imposition of IAEA safeguards are preferred at the L-Basin because bundles are more easily moved for verification in the L-Basin than in the RBOF. (It should be noted that if all of the assemblies currently scheduled for receipt are received $[-23,000]$, there will not be enough storage space in RBOF and L-Basin combined to accommodate the material.)

3. Once about 167 fuel assemblies are received, there is enough U-235 inventory ( $25 \mathrm{kgs}$ ) for standard IAEA safeguards implementation. The IAEA safeguards inspection frequency for this fuel is four times yearly; three quarterly interim inspections and one physical inventory verification (PIV).

4. IAEA witnessing of cask unloading is not required if the received fuel can be verified in subsequent inspections. Verification is accomplished by counting the assemblies and by measuring less than one percent of the assemblies for the presence of gamma radiation. Measurements likely would be required during each inspection to accommodate the receipts since the previous inspection. Opening of selected bundles containing RRSF assemblies may be required.

5. Witnessing of cask unloading by IAEA personnel would be very labor intensive; remote monitoring devices for the irradiated fuel within the facility constraints would be expensive to develop and could provide only ambiguous results.

6. Because of the large number of piecemeal verifications required before the full inventory is reached, the IAEA may prefer for practical reasons to wait until the transfers are complete (for example, all $A B C$, etc.) before verifying and accepting the material under safeguards. The batch submission of subsequent materials (e.g., domestic RRSF) also would be preferred.

7. The SRS operator will contain the RRSF fuel in aluminum tubes (bundles) that will hold up to five assemblies end-to-end. The IAEA and SRS operator must develop methods to verify the fuel present 
in the bundles. Instrumentation already exists in the IAEA for measurement of gamma radiation, but identification of highly enriched uranium (HEU) within the bundles is not now possible with IAEA instruments. Therefore, the IAEA will require that a measurement location be established in the basin and that the operator move selected bundles to that location for measurement. Measurement scans of the length of the bundles likely can establish the number of contained assemblies and the expected cosinusoidal axial activity profile.

8. The IAEA likely also will require that some number of bundles be opened to verify that the contents indeed are RRSF. Alternatively, the United States may wish to support development of a nondestructive measurement device that can qualitatively (or semi-quantitatively) determine the presence (or approximate quantity) of U-235. The measurement may eliminate the need to open bundles for verification of contents.

9. Once the bundles are verified by the IAEA, high incentive exists to place the bundles under IAEA seal in the storage racks. Therefore, the IAEA and SRS operator must cooperate to develop and install a containment structure above the fuel bundle storage racks that can be secured with IAEA cable (fiberoptic or cup wire) seals. The safeguards effort required for the full L-Basin RRSF fuel inventory (8500 assemblies) with and without sealing is:

With Sealing:

Interim insp: Verify 12 seals, count underlying bundles

PIV: $\quad$ Verify 12 seals, count underlying bundles

Without Sealing:

Interim insp: Remove and scan 12 bundles by gamma NDA

PIV:

Remove and scan 36 bundles by gamma NDA 


\subsection{Introduction and Background}

In response to current U.S. nonproliferation policy and obligations under the voluntary offer agreement with the International Atomic Energy Agency (IAEA), the U.S. Department of Energy International Safeguards Division (NN-44) has been working with several program offices and sites throughout the DOE complex to identify facilities and material that may be suitable for placement on the eligible facilities list. In addition, the DOE's program to encourage the return of foreign research reactor spent fuel (RRSF) (of United States origin) will result in the receipt of about 20 metric tons of fuel containing approximately 5 metric tons of highly enriched uranium (HEU) over the next 10-13 years. In the summer of 1996, the planning for the receipt of this RRSF highlighted the fact that storage facilities for such material at the Savannah River Site (SRS) currently are not eligible for IAEA safeguards.

Some of this RRSF is coming from countries such as Argentina, Brazil, and Chile (ABC) that have agreements with the IAEA to continue international safeguards on such material upon return to the United States. Since SRS basins are not currently on the eligible facilities list, the first load of RRSF from Chile had to be removed from IAEA safeguards when it arrived in October 1996. The IAEA is considering applying safeguards at the Oak Ridge High Flux Isotope Reactor (HFIR) in order to meet its obligations to maintain safeguards on an equivalent portion of spent fuel.

To consider the spent fuel storage facilities at SRS as potential candidates for the eligible facilities list, EM-62, EM-63, and NN-44 agreed to conduct an assessment to evaluate the impact of adding these facilities. The results would be used to help EM-63 estimate the cost of preparing one or more of the spent fuel storage basins at SRS for implementation and continuing maintenance of IAEA safeguards.

The assessment was conducted during the week of February 10, 1997, by a team comprised of U.S. national laboratory personnel with experience in IAEA safeguards and in the implementation of IAEA safeguards at U.S. facilities and DOE NN-44 and SRS personnel. The first step in the process was to gather information to make an eligibility determination. Next, the team focused on identifying requirements for the implementation and maintenance of international safeguards and postulating a safeguards approach that might be employed by the IAEA. This report documents the results.

\subsection{Eligibility Determination}

The Receiving Basin for Offsite Fuel (RBOF) and the L-Area Disassembly Basin (L-Basin) currently have no national security mission. There is no material now in either basin that is associated with restricted data. No material is anticipated for future storage that contains or would reveal restricted data. Therefore, both basins meet the requirements for eligibility for implementation of IAEA safeguards. 


\subsection{Facility Descriptions and Operations}

\subsection{Spent Fuel Storage Configuration at SRS}

The SRS has received spent fuel from foreign research reactors for many years. The assemblies received from foreign reactors normally had been under IAEA safeguards in the country of use before being shipped to SRS. Presently, when the casks arrive at SRS any IAEA seals present are removed and returned to the IAEA either directly or through the Euratom safeguards agency. The seals are verified by the IAEA in Vienna to ensure the fuel assemblies destined for SRS were received without compromise. The SRS is scheduled to receive approximately 23,000 fuel assemblies from both domestic and foreign research reactors. The HEU (approximately 5 metric tons) contained in these assemblies is part of the excess fissile material that the United States has committed to making eligible for IAEA safeguards.

The only two facilities at SRS currently identified as potentially amenable for IAEA safeguards are RBOF and L-Basin. Each of these facilities is operational and has spent fuel in storage. The combined storage capacity of the two facilities is approximately 16,200 elements. The available storage is not sufficient to accommodate the total assemblies scheduled for receipt, so some of the material must eventually be stored elsewhere or moved as a result of final disposition decisions.

The term facility is used domestically to refer to the entire structure or operating area. It should be noted clearly that the following descriptions refer to the operations area of the spent fuel basins and are not applicable directly to an IAEA facility description. The cases addressed in Section 6.0 suggest that only portions of the facilities may be included in the safeguarded facility description. Descriptions of the facilities and a brief synopsis of operations follows.

\subsection{Receiving Basin for Offsite Fuel (RBOF)}

The RBOF provides storage for spent nuclear fuel elements from test and research reactors, both domestic and foreign. It has been operating and receiving offsite fuel since 1964 . The facility has an unloading basin, two storage basins, a repackaging basin, a disassembly basin, and an inspection basin, all of which are under water. The storage capability of RBOF is approximately 7,000 Material Test Reactor Equivalent (MTRE) assemblies, and an additional 700 MTRE spaces are being added. The basins are interconnected by transfer canals. An overhead monorail hoist transfer system moves the individual fuel elements through canals to work basins, as required, and finally to the storage location.

Current examples of receiving and storage activities of safeguards interest at RBOF:

- The spent fuel casks are unloaded at RBOF using a crane and are transferred to the unloading basin. 
- If the cask is sealed with an IAEA seal, it is removed and returned to the IAEA through the U.S. State Department.

- The cask is opened, and fuel assemblies are unloaded.

- As the fuel elements are removed from the cask, they are identified by serial number and transferred to baskets for temporary storage.

- The baskets are transferred to the unpacking area for processing.

- In the processing area the end pieces, used for handling, are normally removed using an underwater saw. This operation is designed to leave the serial numbers undisturbed, but occasionally the operation may remove a portion or the entire serial number.

- The fuel elements are then transferred to an aluminum tube for storage (referred to as bundling). Depending on the fuel configuration, from 3 to 6 RRSF elements are normally stored in each bundle.

- When the bundle is full, a serial-numbered cap is put in place. Accountability is maintained by assigning the serial numbers for each fuel element to the aluminum storage bundle.

- The bundle is then transferred to a storage position and logged into the operator's basin storage map.

\subsection{L-Basin}

It is anticipated that RBOF will soon reach capacity. Therefore, L-Basin has been designated by DOE as an alternate spent nuclear fuel (SNF) storage facility to provide uninterrupted fuel receipts. The LBasin has been modified and made ready for its new mission. The facility will provide storage for approximately 8,500 MTRE and 800 SRS fuel elements. The L-Basin is located on the west end of the $105-\mathrm{L}$ building and is a large open bay structure of approximately 33,000 square feet.

Examples of receiving and storage activities of safeguards interest at L-Basin are:

- When a fuel cask arrives at the transfer bay, it is checked for integrity (seals checked and removed) and contamination.

- The cask is opened, and each fuel assembly is removed from the cask and identified by serial number and placed in a transfer bucket.

- When a predetermined number of assemblies have been placed in the bucket, a hoist is used to transfer the bucket to the bundling station in the machine basin.

- At the bundling station, the end pieces used for handling are removed from the assembly with an underwater saw. This operation is designed to leave the serial numbers undisturbed, but occasionally a portion or the entire serial number is removed. 
- The assemblies are placed in an aluminum storage tube (bundle) using a special tilting table designed for this operation.

- When a predetermined number of assemblies (3-5) have been placed in the storage bundle, the table is tilted to an upright position and closed with a non-removable cap.

- Each bundle is assigned a unique serial number that is placed on the cap with lettering that will be readable while the bundle is in storage.

- The storage bundle is then moved to Vertical Tube Storage (VTS) using a crane and chain hoist. Once in the VTS, the tube is placed in a designated storage position.

\subsection{Receipt and Loading Schedules}

The current SRS SNF Unloading Schedule indicates that approximately 100 research reactor spent fuel assemblies will be received each month during a two-year period that began in October 1996. Cask unloading and bundle preparation activities normally are accomplished within a 100-working-hour period. The duration of the unloading and bundling operation provides an estimate of inspector time that would be required to verify each receipt.

\subsection{Summary of IAEA Safeguards Criteria for SRS Research Reactor Spent Fuel}

Criteria applicable to the research reactor fuel being shipped to and stored at the SRS L-Basin and RBOF are contained in Section 9 of the IAEA Safeguards Criteria (hereafter called the Criteria). Most, if not all, of the fuel (spent fuel, as described in the Criteria) will be irradiated. The Criteria requirements generally are presented in 17 paragraphs. Not all paragraphs apply to the scenario at SRS. A complete analysis of the Criteria is in the Appendix. Only the salient paragraphs of the Criteria appear in the following.

1. Examination of records and reports

The facility will maintain a set of records that the IAEA will examine and compare with the accounting reports generated under the structure and content of agreements between the IAEA and States required in connection with the Treaty on the Non-Proliferation of Nuclear Weapons. These records will include Inventory Change Reports (ICRs), Physical Inventory Listings (PILs), and Material Balance Reports (MBRs). Records that should be maintained for a basin storage facility include: a materials ledger (having total book inventory according to location), material transfer papers (documenting transfers within the basins), fuel location maps, and shipping documents. The IAEA will expect to see a List of Inventory Items (LII) that can be reconciled with the PIL from the previous material balance period plus any subsequent ICRs. 
A physical inventory verification (PIV) verifying the operator's own physical inventory must be conducted annually with the period between successive PIVs not exceeding 14 months. The stipulations for verification measures applicable to the inventory are those stated for spent fuel and are contained in paragraphs 2.2 and 2.7 of the Criteria.

The IAEA maintains various detection probabilities related to the overall probability of detecting the absence of a specified quantity of nuclear material. Spent fuel not under containment or surveillance must be item-counted and verified for gross defects at a medium detection probability. Based on requirements for irradiated fuel, a medium detection probability verification for assemblies each having an average of $150 \mathrm{~g}$ of $\mathrm{U}-235$ would require the verification of $0.415 \%$ of all assemblies in the sample stratum. The IAEA adds the requirement that verification must be performed on at least three items for each verification method employed. Verification equipment includes gross gamma (dose-measuring) instruments. Occasionally, high-resolution detectors (cooled intrinsic germanium or ambient temperature CdTe detectors with lower resolution) are used to identify fission product spectra. The use of high-resolution detectors is not specified in the Criteria, however.

For assemblies contained in bundles that cannot be opened, the terms stated under paragraph 6.2(a) and (c) of Annex F of the Criteria (Procedures for Sampling Plans) apply. The bundles would be counted, and an external gamma measurement would be performed on the randomly selected bundles identified in the sampling plan. Because the number of individual items (fuel assemblies) would be the number used in the sampling plan, the number of bundles measured would be $0.415 \%$ of the number of assemblies (not $0.415 \%$ of the bundles).

The verification would require movement of the bundle from the storage location (to lower the background level and eliminate interference from other bundles in the storage rack). The Criteria require this measurement to verify that the number and types of items in the bundle are correct. A gross gamma scan likely would satisfy this requirement, but some tests with a collimated gamma detector (e.g., CdTe in tantalum) would be necessary to demonstrate that the axial gamma profile from the bundle corresponds to the expected radiation profile. Adjacent fuel assemblies (above/below) in the bundle with radically different exposures or cooling times could be a problem. Tests are required to determine if these measurements could be performed just by moving the bundles vertically from the storage locations in the L-Basin. Vertical movement is more constrained in RBOF.

Surveillance is not attractive for the basin areas because of the many movements in the surveillance view. With inconclusive surveillance (showing movement), measurement verification is the same as without surveillance. If the bundles in racks could be sealed, PIV measures would simply involve a replacement of seals at a low detection probability and accounting of the bundles under seal (Annex F, paragraph 6.1(d) of the Criteria). Even when all assemblies are in the basin, this would only involve the replacement of about 12 seals during each inspection.

3. Verification of Domestic and International Transfers

Transfers are verified at PIVs and at interim inspections (conducted quarterly) to the same level as at the PIV. Thus, it is expected that inspectors will perform measurements with each inspection during 
the fuels return campaign. Again, if surveillance is used, complications arise because of the requirement that movement of the containers must be verified.

\section{Verification Activities at Interim Inspections for Timely Detection}

Verifications are conducted once each calendar quarter for facilities with a quantity of nuclear material equal to or greater than one significant quantity (SQ). One SQ of U-235 is $25 \mathrm{~kg}$. For fuel containing an average of 150 grams of U-235 per assembly, one SQ is 167 assemblies. For fuel not under containment and surveillance, the material is item-counted and verified at low detection probability ( $0.134 \%$ of the assemblies) for gross defects (see PIV requirements above for measurement approaches). This detection probability is based on an average U-235 loading of 150 grams per assembly. If the material is under IAEA seal, seals are replaced and verified with a low detection probability based on the material quantities contained under each seal.

\section{Verification of Design Information .}

The United States must submit design information on the facility and also must notify the IAEA of any important changes in the design information. Design information includes not only the details of the physical construction but also bookkeeping information. Design information is provided by the facility on IAEA-supplied forms requesting relevant construction and operational information.

\subsection{Measurements}

Measurement verification is necessary for initial inventory verification and interim inspections. The main purpose of the IAEA NDA measurement is to detect gross defects (presence or absence of material) in the declared quantities of material. A customized detector designed for specific basin installation can be developed utilizing existing components and optimized for the bundles at RBOF and L-Basin; bundle sizes are different at the two facilities. The detector can be installed permanently at the unloading basin or it can be portable. In L-Basin, a portable detector is preferable because the basin is deep compared to the bundle length. Bundles can be left in storage racks and the detector moved to the bundle, where verification measurements are made. This can potentially reduce the operator's effort. In the RBOF facility, it would be preferable to install the detector permanently at the unloading basin.

Research reactor spent fuel containing HEU does not contain enough plutonium to provide a passive neutron signal sufficient for accurate measurement. Verification of these fuels has to rely on the passive gamma signature from the fission products or from active interrogation of residual fissile content. The gross gamma emission can be measured with ion chambers; gamma-ray spectroscopy can be obtained with high-resolution detectors such as CdTe or Ge. Active interrogation can be performed with AmLi neutron sources and neutron coincidence counting of the fission neutrons. For simplicity of operation and to provide the potential of an unattended mode, the ion chamber approach is recommended.

If a detector is installed and if the order of assembly loading is known, it would be advantageous to request the operators to scan some of the bundles as soon as they are packaged. This would provide a 
useful correlation between the operator-declared fuel burn-up and the gross gamma counting rate. The inspectors can request verification of these bundles and correct for radioactive decay. This would reduce the inspection effort and increase inspector confidence in the verification measurement.

\subsection{Containment/Surveillance Options}

Storage facility PIV requirements specify that material not under containment and surveillance (C/S) must be verified with a medium detection probability for gross defects $(0.415 \%$ of all assemblies). Although this is usually accomplished using gross gamma measurement or Cerenkov glow observation, this would be difficult and time-consuming for bundled fuel. Some form of containment or surveillance must be utilized to minimize the amount of material subject to this yearly reverification.

\subsection{Seals}

Seals provide one option for mitigating the aforementioned requirement. IAEA criteria state that "for that part of the spent fuel under single C/S based on seals, the seals are verified with low detection probability, and the sealed items selected for seal verification are item counted" [IAEA Safeguards Criteria 4-2.5(c)]. Seals verified with a "low detection probability" means that only a few seals will be selected for verification. Verification can be accomplished at the facility for some types of seals; others must be replaced and the detached seals are then verified at IAEA headquarters. A similar requirement exists for interim inspections; however, in this case the sealed items are not counted. The items verified for interim inspections would not be individual assemblies because they are in containers.

Since spent fuel assemblies are consolidated into bundles upon arrival at the facility, the best means of ensuring the containment integrity of this material is by using seals applied to caps on the bundles themselves. This option is not a viable one, however, for two reasons:

1. Bundles cannot be opened without cutting off their tops; consequently, reverifying the contents of a bundle requires its destruction.

2. Each applied seal would have to be verified above the basin waterline. This can be accomplished easily using optical seals, but applying an optical seal to each container would be very difficult and expensive. It would also preclude movement of the bundle, since such movement would be hazardous for the attached wire.

Instead, it would be expedient to devise a mechanism (perhaps only a bar or plate) that will prevent the undetected removal of an entire row of bundles from the rack in which they reside. Once this mechanism is sealed, there will be reasonable assurance that no bundle has been removed or has had its contents replaced during the inspector's absence.

This is not a novel concept; there have been similar IAEA seal applications in Ukraine. Thousands of spent fuel assemblies are currently under seal at Chernobyl. These seals are located at deck level and can 
be verified while attached. The seals are attached to bars that prevent the removal of any fuel assembly from its rack. One hundred percent seal verification can be accomplished in less than an hour. As another example, VVER-440 spent fuel assemblies in the lower rack of the of the spent fuel basin at the Rovno facility have been sealed by applying twin seals on the upper fuel rack, which prevents access to the lower rack.

Any seal application scheme would not eliminate the requirement for full verification of the material before sealing. Unsealed material would have to be verified with low detection probability for gross defects during interim inspections and at medium detection probability during PIVs.

\subsection{Surveillance}

Automated surveillance on sealed, previously inventoried material would not provide additional benefits. However, surveillance is requisite for maintaining control of material during unloading, consolidation, and manipulation. Providing surveillance during these operations would be extremely costly and perhaps impossible. Some combination of seals, surveillance, and inspector vigilance would be required to effect continuity of knowledge on fuel assemblies from seal detachment through final storage.

\subsection{Cases}

Three cases were considered for the specification of anticipated IAEA requirements. This was done to provide firm bases for development of the specifications for initial preparations and ongoing interaction of inspection activities with basin operations. These cases are:

1. Offer for IAEA safeguards only the RRSF covered by agreements specifying continuation of safeguards after return to the United States, e.g., ABC, including material to be received from these countries in future years

2. Offer all foreign RRSF in the basins plus new shipments as they arrive, regardless of the terms of the agreements each country has with the IAEA

3. Offer all RRSF spent fuel in the two basins and the contents of future shipments, both foreign and domestic.

The initial preparations for all cases are similar. However, the level of subsequent actions and impacts increases with each case. The Case 1 offer allows the United States to assist in the maintenance of existing international agreements. The Case 3 offer maximizes the contribution this project would make toward achieving the aims of Presidential Decision Directive 41. In the case in which only the RRSF being returned from $\mathrm{ABC}$ (and other countries with similar agreements) is considered for safeguards, it is possible that the expense of implementing safeguards at HFIR could be delayed or indefinitely postponed. Since the IAEA is considering selecting HFIR to allow substitution of HFIR spent fuel for the returning 
shipment from Chile, implementing safeguards at SRS and replacing the Chilean fuel under safeguards would eliminate the immediate need for safeguards at HFIR.

Further, the requirements for initial preparations and ongoing inspections will depend upon whether or not current IAEA inspection criteria will be applied. If inspection procedures can be negotiated with the IAEA that will both achieve IAEA goals and facilitate the United States' desire to minimize the costs and impact of safeguards, then the requirements for both phases will be lessened.

Table 6.1 describes the requirements to be expected in these six instances (three cases with two options each).

Table 6.1. Case Descriptions and Requirements

\begin{tabular}{||l|l|l||}
\hline \multicolumn{1}{|c|}{ Case } & \multicolumn{1}{c|}{ With Sealed Containment } & \multicolumn{1}{c|}{ Without Sealed Containment } \\
\hline $\begin{array}{l}\text { Case 1 - ABC RRSF } \\
\text { (700 Assemblies) }\end{array}$ & $\begin{array}{l}\text { Interim - Verify 3 seals, count }{ }^{\text {(a) }} \\
\text { PIV - Check 3 seals, count }\end{array}$ & $\begin{array}{l}\text { Interim-NDA Scan 3 Bundles } \\
\text { PIV }\end{array}$ \\
\hline $\begin{array}{l}\text { Case 2 - L-Basin } \\
\text { (8,500 Assemblies) }\end{array}$ & $\begin{array}{l}\text { Interim - Check 12 seals, count } \\
\text { PIV - Check 12 seals, count }\end{array}$ & $\begin{array}{l}\text { Interim-NDA Scan 12 Bundles } \\
\text { PIV - NDA Scan 36 Bundles }\end{array}$ \\
\hline $\begin{array}{l}\text { Case 3 - L-basin + RBOF } \\
\text { (16,200 Assemblies) }\end{array}$ & $\begin{array}{l}\text { Interim - Check 22 seals, count } \\
\text { PIV - Check 22 seals, count }\end{array}$ & $\begin{array}{l}\text { Interim-NDA Scan 22 Bundles } \\
\text { PIV - NDA Scan 68 Bundles }\end{array}$ \\
\hline $\begin{array}{l}\text { (a) Count underlying bundles. } \\
\text { (b) Gamma scan. }\end{array}$ & \\
\hline
\end{tabular}




\subsection{IAEA and Operator Resource Requirements}

Resource obligations for both the IAEA and operator/United States are incurred for all cases. Areas requiring resource commitment are preparations for routine inspection, initial inventory verification, interim inspections, and annual PIVs.

\subsection{Routine Inspections}

Preparations for routine inspections involve the following tasks:

1. Preparation and verification of the design information questionnaire (DIQ)

2. Review and negotiation of a facility attachment.

3. Preparation of reports system amenable to IAEA requirements.

4. Preparation of a fuel verification plan and apparatus for the IAEA. For example, the operator may design a light pipe on the basin wall for the gross gamma scanning of fuel bundles (gamma profile); a collimated LAEA-owned CdTe detector could be used. An equivalent design and acceptable measurement procedure might be to place the collimated measurement detector at the top of a rack storage position and slowly raise the bundle to scan the bundle axially. The fuel verification plan should be prepared in consultation with the IAEA.

5. Preparation of rack sealing. The operator, in conjunction with the IAEA, should develop sealable hardware to fit over the storage rack that prevents the fuel from being removed from the rack. The sealing arrangement should allow fiber-optic seals (which can be verified in the field) to be used. Thus, the seals and cables should be kept dry and uncontaminated. The incentive for this is elimination of any further measurements. The fuel must be verified at medium detection probability, $0.415 \%$, for gross defects before being sealed.

The IAEA and operator resource requirements during the three quarterly interim inspections (for timeliness) and during the annual PIV are different and depend on successful seal application.

\subsection{Initial Inventory Verification}

The material (assemblies and bundles of assemblies) already in the basins and being submitted to IAEA safeguards must be item counted to confirm the population and verified (according to PIV requirements described below) by gross defect measurement (gamma radiation profile) at random medium level $(0.415 \%$ of the assemblies). The material should be put under seal once verified, if sealing arrangements have been made. 


\subsection{Interim Inspections}

The IAEA quarterly interim inspection will involve verification of receipts that have arrived since the previous inspection. The verification must be done to the same degree as the PIV and thus will include item counting to establish the number of receipts and gross defects test for about $0.415 \%$ of the estimated 400 items received each quarter (see Section 3.0, Safeguards Criteria item 3). For 400 assemblies this would amount to only two items. The verified and bundled assemblies should be put under seal as soon as they are verified.

Fuel that is not part of the received inventory and not under seal must be measured for gross defects at low detection probability (about $0.134 \%$ ). For fuel in bundles, the sampling plan must consider the contained assemblies, not the bundles, to be the accountable unit. Thus, the actual number of assemblies measured for gross defects would be, on average, four times higher (i.e., four assemblies per bundle). If no sealing were ever used and the inventory reached 8,500 assemblies, about 12 bundles would have to be scanned during each interim inspection.

If groups of bundles (containing 100 assemblies on average) were under seals instead, $13 \%$ of the 85 seals would have to be verified (i.e., 12 seals).

The shipping documents must be reviewed and compared with the Inventory Change Reports (ICRs) submitted to the IAEA by the shipping and receiving countries.

\subsection{Physical Inventory Verifications}

The IAEA PIV takes place after the Physical Inventory Taking (PIT) of the operator. The PIV occurs annually with no more than 14 months between successive PIVs. The inspection during the PIV also can be used to verify the receipts of spent fuel to the facility, and thus, the measurement activities are the same as at the interim inspection. Measurements would be made on two of the 400 assemblies received. They are measured for gross defects.

If no sealing were present, the bundles would have to be measured by a random medium sampling intensity that takes into account contained assemblies, not bundles. The bundles must be scanned to verify the number of contained items and confirm that the gross signature is consistent with the contained assemblies. Again, $0.415 \%$ of the assemblies would be subject to gross measurements. However, since each bundle contains four assemblies, on average, the number of assemblies actually measured would be 4 $x 0.415 \%$ or about $1.7 \%$. The number of bundles also would be about $0.415 \%$ (there is little chance that two assemblies would be picked from the same bundle). If no sealing were ever used and the total inventory reached 8,500 elements (L-Basin), about 36 bundles would have to be scanned during each PIV.

For material under seals, seals would be exchanged and verified at random low probability (again, about $13 \%$ of the seals), and the number of bundles under each removed seal would be counted.

The records and reports (ICRs, MBR, and PIL) must be compared. Records include the list of inventory items, fuel basin maps, transfer records, nuclear material item transfer forms, and the fuel ledgers. 
Table 7.1 and 7.2 describe the facility impacts from IAEA selection activity.

Table 7.1. Facility Selection Impacts

Impacts of Facility Selection for IAEA Safeguards

\begin{tabular}{|l|l|}
\hline \multicolumn{1}{|c|}{ IAEA Activity } & \multicolumn{1}{|c|}{ Facility Impact } \\
\hline Design verification & $\begin{array}{l}\text { Preparing design information } \\
\text { Completing design information questionnaire } \\
\text { Assisting IAEA in facility design review }\end{array}$ \\
\hline Review of accountability reports & $\begin{array}{l}\text { Developing a database with all information required } \\
\text { by the IAEA }\end{array}$ \\
\hline Verification of spent fuel in storage bundles & $\begin{array}{l}\text { Installing and operating a measurement station for } \\
\text { IAEA equipment }\end{array}$ \\
\hline $\begin{array}{l}\text { Application of seals for containment between } \\
\text { inspections }\end{array}$ & $\begin{array}{l}\text { Developing a mechanism for facilitating the IAEA } \\
\text { attachment of seals to groups of bundles }\end{array}$ \\
\hline
\end{tabular}

Table 7.2. Facility Operations Impacts

Impacts of Selection on Facility Operation Schedule

\begin{tabular}{||l|l||}
\hline \multicolumn{1}{|c|}{ IAEA Activity } & \multicolumn{1}{|c|}{ Facility Impact } \\
\hline Design verification & Assisting IAEA in facility design review \\
\hline Review of accountability records and reports & $\begin{array}{l}\text { Preparing inventory lists and reports for IAEA } \\
\text { inspection }\end{array}$ \\
\hline Verification of spent fuel in storage bundles & $\begin{array}{l}\text { Moving selected bundles to measurement station } \\
\text { for verification } \\
\text { Opening of selected bundles and removing } \\
\text { assemblies for visual inspection }\end{array}$ \\
\hline $\begin{array}{l}\text { Application of seals for containment between } \\
\text { inspections }\end{array}$ & $\begin{array}{l}\text { Facilitating equipment installation and assisting in } \\
\text { seal verification activities }\end{array}$ \\
\hline
\end{tabular}




\section{Appendix}

IAEA Safeguards Criteria for Research Reactor Fuel 


\section{Appendix}

\section{IAEA Safeguards Criteria for Research Reactor Fuel}

1. Examination of records and reports

The facility will maintain a set of records that the IAEA will examine and compare with the accounting reports generated under the structure and content of agreements between the IAEA and United States required in connection with the Treaty on the Non-Proliferation of Nuclear Weapons (INFCIRC/153). These records will include Inventory Change Reports (ICRs), Physical Inventory Listings (PILs), and Material Balance Reports (MBRs). Records that should be maintained for a basin storage facility include: a materials ledger (having total book inventory according to location), material transfer papers (documenting transfers within the basins), fuel location maps, and shipping documents. The IAEA will expect to see a List of Inventory Items (LII) that can be reconciled with the PIL from the previous material balance period plus any subsequent ICRs.

2. Physical Inventory Verification (PIV)

A physical inventory verification (PIV) verifying the operator's own physical inventory taking must be conducted annually with the period between successive PIVs not exceeding 14 months. The stipulations for verification measures applicable to the inventory are those stated for spent fuel and are contained in paragraphs 2.2 and 2.7 of the Criteria.

The Agency maintains various detection probabilities related to the overall probability of detecting the absence of a specified quantity of nuclear material. Spent fuel not under containment or surveillance must be item counted and verified for gross defects at a medium detection probability. A medium detection probability verification for assemblies having an average of $150 \mathrm{~g}$ of U-235 (each) would require the verification of $0.415 \%$ of all assemblies in the sample stratum. The IAEA adds the requirement that verification must be performed on at least three items for each verification method employed. Verification equipment includes gross gamma (dose-measuring) instruments.

Occasionally, high-resolution detectors (cooled intrinsic germanium or ambient temperature CdTe detectors with lower resolution) are used to identify fission product spectra. The use of high-resolution detectors is not specified in the Criteria, however.

For assemblies contained in bundles that cannot be opened, the terms stated under paragraph 6.2(a) and (c) of Annex F of the Criteria (Procedures for Sampling Plans) apply. The bundles would be counted and an external gamma measurement would be performed on the randomly selected bundles identified in the sampling plan. Because the number of individual items (assemblies) would be the number used in the sampling plan, the number of bundles measured would be $0.415 \%$ of the number of assemblies (not $0.415 \%$ of the bundles). 
The verification would require movement of the bundle from the storage location (to lower the background level and eliminate interference from other bundles in the storage rack). The Criteria require this measurement to verify that the number and types of items in the bundle is correct. A gross gamma scan likely would satisfy this requirement but some tests with a collimated gamma detector (e.g., CdTe in tantalum) would be necessary to demonstrate that the axial gamma profile from the bundle corresponds to the expected radiation profile. Adjacent fuel assemblies in the bundle with radically different exposures or cooling times could be a problem. Tests are required to determine if these measurements could be performed just by moving the bundles vertically from the storage locations in the L-Basin. Vertical movement is more constrained in RBOF.

Surveillance is not attractive for the basin areas because of the many movements in the surveillance view. With inconclusive surveillance (showing movement), measurement verification is the same as without surveillance. If the bundles in racks could be sealed, PIV measures would simply involve a replacement of seals at a low detection probability and a counting of the bundles under seal (Annex F, paragraph 6.1(d) of the Criteria). Even when all assemblies are in the L-Basin, this would only involve the replacement of about 12 seals during each inspection.

3. Verification of Domestic and International Transfers

Transfers are verified at PIVs and at interim inspections (conducted quarterly) to the same level as at the PIV. Thus, the inspectors are expected to perform measurements with each inspection during the fuels return campaign. Again, if surveillance is used, complications arise because of the requirement that movement of the containers be verified.

\section{Verification of Other Inventory Change}

Nuclear material becoming subject to safeguards is verified during inspections for other purposes (interim inspections) to the same standards as during the PIV. Such situations may arise when safeguards begin on the basins and also may be the case if safeguards on shipments from foreign countries lapses for any reason. This is also the case if U.S. fuel (from domestic reactors) enters safeguards.

5. Verifications at Other Strategic Points

Not applicable.

6. Confirmation of the Absence of Unreported Production of Direct-Use Material from Material Subject to Safeguards

Not applicable.

7. Confirmation of the Absence of Borrowing of Nuclear Material

This requirement is practically impossible in the United States because much of the U.S. nuclear program is outside IAEA safeguards.

8. Material Balance Evaluation 
Because this is an item facility, Material Unaccounted For (MUF) should be zero. However, it is conceivable that shipper/receiver differences could arise if the operator does not accept the shipper's material values. The IAEA must evaluate this difference for significance.

\section{Verification Activities at Interim Inspections for Timely Detection}

Verifications are conducted once each calendar quarter for facilities with a quantity of nuclear material in respect of which the possibility of manufacturing an explosive device cannot be excluded ( $>1$ significant quantity [SQ]). One SQ of U-235 is $25 \mathrm{~kg}$ and is equivalent to $167 \mathrm{RRSF}$, each containing an average of 150 grams. For fuel not under containment and surveillance, the material is item counted and verified at low detection probability $(0.134 \%$ of the assemblies) for gross defects (see PIV requirements above for measurement approaches). If the material is under IAEA seal, seals are replaced and verified with a low detection probability based on the material quantities contained under each seal.

10. Discrepancy and Anomaly Follow-up

A discrepancy is an inconsistency within the operator's statements or between the operator's statements and the inspector's observations. An anomaly is an unusual observable condition that might occur in the event of a diversion or misuse of nuclear material, equipment, or facilities. The lower limit for an anomaly is $0.1 \mathrm{SQ}$. Anomalies and discrepancies totaling more than $1 \mathrm{SQ}$ at the end of the material balance period must be resolved by 15 April of the following year.

11. Verification of Design Information

The United States must submit design information on the facility and also notify the IAEA of any important changes in the design information. Design information includes not only the details of the physical construction but also safety, operations, nuclear material control, and bookkeeping information. Design information is provided by the facility on IAEA-supplied forms requesting relevant construction and operation information.

12. Verification of Operator's Measurement System

The operator's measurement system generally will be used to confirm shipper's data. Shipper's data will be used for accounting unless significant discrepancies are discovered.

13. Confirmation of Transfers

All receipts (and shipments) recorded by a facility are confirmed by comparison with the reports and records of the corresponding facility. 
14. Activities When Inventory is Less Than 1 Significant Quantity and Used for the Evaluation of Partial Attainment of the Inspection Goal When Inventory is Greater than 1 Significant Quantity

Only partial attainment of the IAEA's inspection goal would be achieved if low (instead of medium) detection probability measurements were made on fuel not under seal. This is also true if insufficient verification of any seals were performed or if verification of transfers were inadequate.

15. Activities Related to Non-Nuclear Material under Safeguards

Not applicable.

16. Activities Related to Equipment and Facilities under Safeguards

Not applicable.

17. Activities Related to the Preparation and Maintenance of Inventories and of Lists of Information Not applicable. 